\begin{tabular}{|l|l|l||}
\hline \multicolumn{2}{|c|}{ PublisherInfo } \\
\hline \hline PublisherName & $:$ & BioMed Central \\
\hline \hline PublisherLocation & $:$ & London \\
\hline \hline PublisherImprintName & $:$ & BioMed Central \\
\hline \hline
\end{tabular}

\title{
Gateway to the worm community
}

\begin{tabular}{|l|l|l||}
\hline \multicolumn{2}{|c|}{ ArticleInfo } \\
\hline \hline ArticleID & $:$ & 4300 \\
\hline \hline ArticleDOI & $:$ & $10.1186 /$ gb-2001-3-1-reports2007 \\
\hline \hline ArticleCitationID & $:$ & reports2007 \\
\hline \hline ArticleSequenceNumber & $:$ & 32 \\
\hline \hline ArticleCategory & $:$ & Web report \\
\hline \hline ArticleFirstPage & $:$ & 1 \\
\hline \hline ArticleLastPage & $:$ & 4 \\
\hline \hline & & RegistrationDate : 2001-11-6 \\
ArticleHistory & $:$ & Received \\
& $:$ OnlineDate $\quad:$ 2001-11-6 \\
\hline \hline ArticleCopyright & $:$ & BioMed Central Ltd2001 \\
\hline \hline ArticleGrants & $:$ & \\
\hline \hline ArticleContext & $:$ & 130593311 \\
\hline \hline
\end{tabular}




\section{Abstract}

This portal to information on Caenorhabditis elegans provides a tremendous service to the dedicated worm community and is also useful for the nonspecialist.

\section{Mirror sites}

the UK mirror of the C. elegans WWW Server.

\section{Content}

This portal to information on Caenorhabditis elegans provides a tremendous service to the dedicated worm community and is also useful for the nonspecialist. Unique features are a robust search engine that allows one to search all the worm literature (including 'unpublished' information from the Worm Breeders' Gazette and meeting abstracts) and information about $C$. elegans for nonspecialists. This website also links to all of the other major worm websites, including WormBase (the genome sequence repository and more), the Caenorhabditis elegans Genetics Center (CGC; the strain repository) and pages with information about $C$. elegans methods, researchers and the newsgroup bionet.celegans, which includes information, discussion and announcements related to C elegans.

\section{Navigation}

No registration is required and anyone can access the site. Once you get there, major links such as 'WormBase', 'Recent papers', 'CGC', 'EM Center', 'Software', 'Literature Search', 'Labs', 'Announcements' and so on, are lined up to choose from. For example, if you click 'Software', you will be given the option of accessing a few software programs, including the $C$. elegansgenome database program ACeDB. If $\mathrm{ACeDB}$ is clicked, you will be given a brief description of its features and a link to the AceDB homepage. Navigating through the links is easy and the site is very user-friendly. 


\section{Reporter's comments}

\section{Timeliness}

The site is updated daily.

\section{Best feature}

The literature search feature is excellent due to its comprehensive coverage of all the past and recent literature including meeting abstracts.

\section{Worst feature}

Updates on worm lab information were unsatisfactory as some of the links were out-of-date.

\section{Related websites}

Related websites WormBase provides a repository of mapping, sequencing and phenotypic information about $C$. elegans and some closely related nematodes. It includes the essentially complete genomic sequence.

\section{Table of links}

Caenorhabditis elegans WWW Server

the UK mirror of the C. elegans WWW Server

WormBase

Caenorhabditis elegans Genetics Center

AceDB 


\section{References}

1. Caenorhabditis elegans WWW Server.

This PDF file was created after publication. 